(1)

CrossMark

\title{
Endothelial cell dysfunction: a major player in SARS-CoV-2 infection (COVID-19)?
}

\author{
Alice Huertas (1) ${ }^{1,2,3}$, David Montani (i) ${ }^{1,2,3}$, Laurent Savale (1) ${ }^{1,2,3}$ \\ Jérémie Pichon ${ }^{1,2,3}$, Ly Tu (10 ${ }^{1,2}$, Florence Parent ${ }^{1,2,3}$, Christophe Guignabert (10 ${ }^{1,2}$ \\ and Marc Humbert (10 ${ }^{1,2,3}$
}

Affiliations: ${ }^{1}$ Université Paris-Saclay, School of Medicine, Le Kremlin-Bicêtre, France. ${ }^{2}$ INSERM UMR_S 999 «Pulmonary Hypertension: Pathophysiology and Novel Therapies», Hôpital Marie Lannelongue, Le PlessisRobinson, France. ${ }^{3}$ Assistance Publique - Hôpitaux de Paris (AP-HP), Department of Respiratory and Intensive Care Medicine, Pulmonary Hypertension National Referral Center, Hôpital Bicêtre, Le Kremlin-Bicêtre, France.

Correspondence: Alice Huertas, INSERM UMR S 999, Hôpital Marie Lannelongue 133, Avenue de la Résistance 92350, Le Plessis-Robinson, France. E-mail: alice.huertasQinserm.fr

@ERSpublications

Endothelial cell dysfunction and impaired microcirculatory function contribute markedly to lifethreatening complications of COVID-19, such as venous thromboembolic disease and multiple organ involvement https://bit.ly/3cZMjKV

Cite this article as: Huertas A, Montani D, Savale L, et al. Endothelial cell dysfunction: a major player in SARS-CoV-2 infection (COVID-19)? Eur Respir J 2020; 56: 2001634 [https://doi.org/10.1183/ 13993003.01634-2020].

Coronavirus disease 2019 (COVID-19) represents a public health crisis of pandemic proportions. Caused by the severe acute respiratory syndrome coronavirus 2 (SARS-CoV-2), the symptoms most commonly reported include cough, fever and shortness of breath, but extra-pulmonary symptoms may also be present, such as neurological and gastroenterological manifestations.

The pathogenesis of the disease depends mainly on the mechanisms of entry and action of the coronaviruses. Until 2003, two types of coronavirus surface receptor were known. A number of group I coronaviruses, for example human coronavirus 229E and viruses causing transmissible gastroenteritis and feline infectious peritonitis, require the zinc metallo-protease aminopeptidase N (APN, CD13) for entry into their target cells $[1,2]$. The group II coronavirus mouse hepatitis virus (MHV) uses members of the immunoglobulin superfamily of receptors, such as the murine carcinoembryonic antigen-related cell adhesion molecules (CEACAMs) [3]. Li et al. [4] identified a distinct coronavirus as the aetiological agent of 2003 severe acute respiratory syndrome (SARS), the SARS-CoV-1, which uses a surface glycoprotein called spike $(S)$ to access host cells. Interestingly, SARS-CoV-2 is closely related to SARS-CoV-1, and it was demonstrated that $S$ proteins of coronaviruses need to bind with cellular receptors to mediate infection of their target cells [5]. $\mathrm{Li}$ and co-workers were able to show that a metallopeptidase (angiotensin-converting enzyme 2; ACE-2) [6], isolated from SARS-CoV-permissive Vero E6 cells (African green monkey kidney cell line), could efficiently bind the S1 domain of the SARS-CoV S protein and acted as a functional co-receptor for coronavirus entry. Most recently, ACE-2 has been demonstrated to be a human interferon-stimulated gene, suggesting that SARS-CoV-2 could exploit species-specific interferon-driven upregulation of $\mathrm{ACE}-2$, a tissue-protective mediator during lung injury, to enhance infection [7]. 
The disease pathogenesis also depends on the localisation of the coronavirus co-receptors. As shown by Hamming et al. [8], ACE-2 is abundantly present in humans in the epithelia of lung and small intestine, cells in contact with the external environment, which might provide possible routes of entry for the SARS-CoV-2. This epithelial expression provides a first step in understanding the pathogenesis of the main SARS disease manifestations, in particular in the lung (cough, pneumonia and severe acute respiratory syndrome). Type I and type II pneumocytes are markedly positive for ACE-2, indicating that alveolar pneumocytes are a possible site of entrance for SARS-CoV. Virus entry may cause cytopathological changes at the epithelial alveolo-capillary interface, initially resulting in induction of type II alveolar cells as a first attempt to repair. In SARS, the abundant expression of ACE-2 in type II alveolar cells may cause rapid viral expansion and local alveolar wall destruction, resulting in rapidly progressive severe diffuse alveolar damage and hyperinflammation known as cytokine storm syndrome [9]. Moreover, it has been demonstrated that oxidative stress induced by SARS-CoV-2 can exacerbate DNA methylation defect, possibly resulting in further ACE2 demethylation and enhanced viraemia [10]. Oxidative stress in the lung occurs when the antioxidant capacity is overwhelmed or depleted through external exposures, such as altered oxygen tension or air pollution, or internally by activation of resident cells or inflammatory cells recruited in response to an exposure, injury or infection [11, 12]. Interestingly, АвоuнASHEм et al. [13] have recently shown, through single cell RNA sequencing data of the human lungs, that specific components of the antioxidant defence system of the alveolar type II cells, such as superoxide dismutase 3 and activating transcription factor 4 , an endoplasmic reticulum stress sensor, weaken in response to ageing in elderly donors. These results could contribute in part to the observed severity of COVID-19 in the elderly.

The other targets of SARS-CoV are immune organs and systemic small vessels, resulting in systemic vasculitis and decreased immune function. Other receptors/facilitators on the surface of human cells have been suggested to mediate the entry of SARS-CoV-2, including transmembrane serine protease 2 [14], sialic acid [15] and extracellular matrix metalloproteinase inducer (CD147, also known as basigin) [16].

Interestingly, ACE-2, as well as the other three facilitators, are present in arterial and venous endothelial cells and arterial smooth muscle cells [8]. ACE-2 is the most studied of these receptors/facilitators and questions have been recently raised about using renin-angiotensin-aldosterone system inhibitors, such as angiotensin II receptor blockers (ARB) and ACE inhibitors, for COVID-19 patients with hypertension [17-23]. In particular, data on a potential association between the use of ACE inhibitors or ARBs and the risk of developing SARS-CoV-2 were conflicting. Lately, two distinct studies have demonstrated, in large cohorts of patients, that there was no evidence of an increased risk of COVID-19 due to ACE inhibitor or ARB treatments $[23,24]$. Of interest, it has also been shown that interleukin- 6 produced during the cytokine storm syndrome can also be induced by angiotensin II through a mineralocorticoid receptor-dependent mechanism $[25,26]$.

The expression of ACE-2 on endothelial cells, smooth muscle cells and perivascular pericytes in virtually all organs suggests that the SARS-CoV-2, once present in the circulation, can spread easily through the body [8]. Interestingly, in a recent work comparing post mortem lung tissues from patients who died from COVID-19, acute respiratory distress syndrome due to influenza A (H1N1) infection and age-matched, uninfected control lungs, the authors found greater numbers of ACE-2-positive endothelial cells and significant changes in endothelial morphology with disruption of intercellular junctions, cell swelling, and a loss of contact with the basal membrane [27].

Increasing clinical evidence shows that the most common comorbidities observed in COVID-19 patients, that are associated with worse prognosis and higher rate of death, are systemic hypertension, diabetes and obesity, in which endothelial dysfunction [28] is known to be a key determinant. In this issue of the European Respiratory Journal, two research letters underscore the risk of deep vein thrombosis and acute pulmonary embolism in COVID-19 [29, 30]. These data confirm and extend previous observations supporting an underlying SARS-CoV-2-related endothelial dysfunction with an increased risk of venous thromboembolic disease, systemic vasculitis, endothelial cell apoptosis and inflammation in various organs [31-34]. It is also known that, as other infectious microorganisms, SARS-CoV-2 can activate coagulopathy through inflammatory responses. The discovery that platelet dense granules contain polyphosphates and secrete them upon activation led to the identification of extensive connections between the immune system and the coagulation cascade [35]. Polyphosphates released from activated platelets accelerate factor $\mathrm{V}$ activation, inhibit the anticoagulant activity of tissue factor pathway inhibitor, promote factor XI activation by thrombin, and contribute to the synthesis of thicker fibrin strands that are resistant to fibrinolysis [36]. The inflammatory effects of cytokines also result in activated vascular endothelial cells and endothelial injury with resultant prothrombotic properties. Vascular endothelial injury causes further thrombocytopenia, reduction of natural anticoagulants, and also haemostatic activation as the phenotypic expression of thrombotic diffuse intravascular coagulation. In COVID-19-associated coagulopathy [37], the 


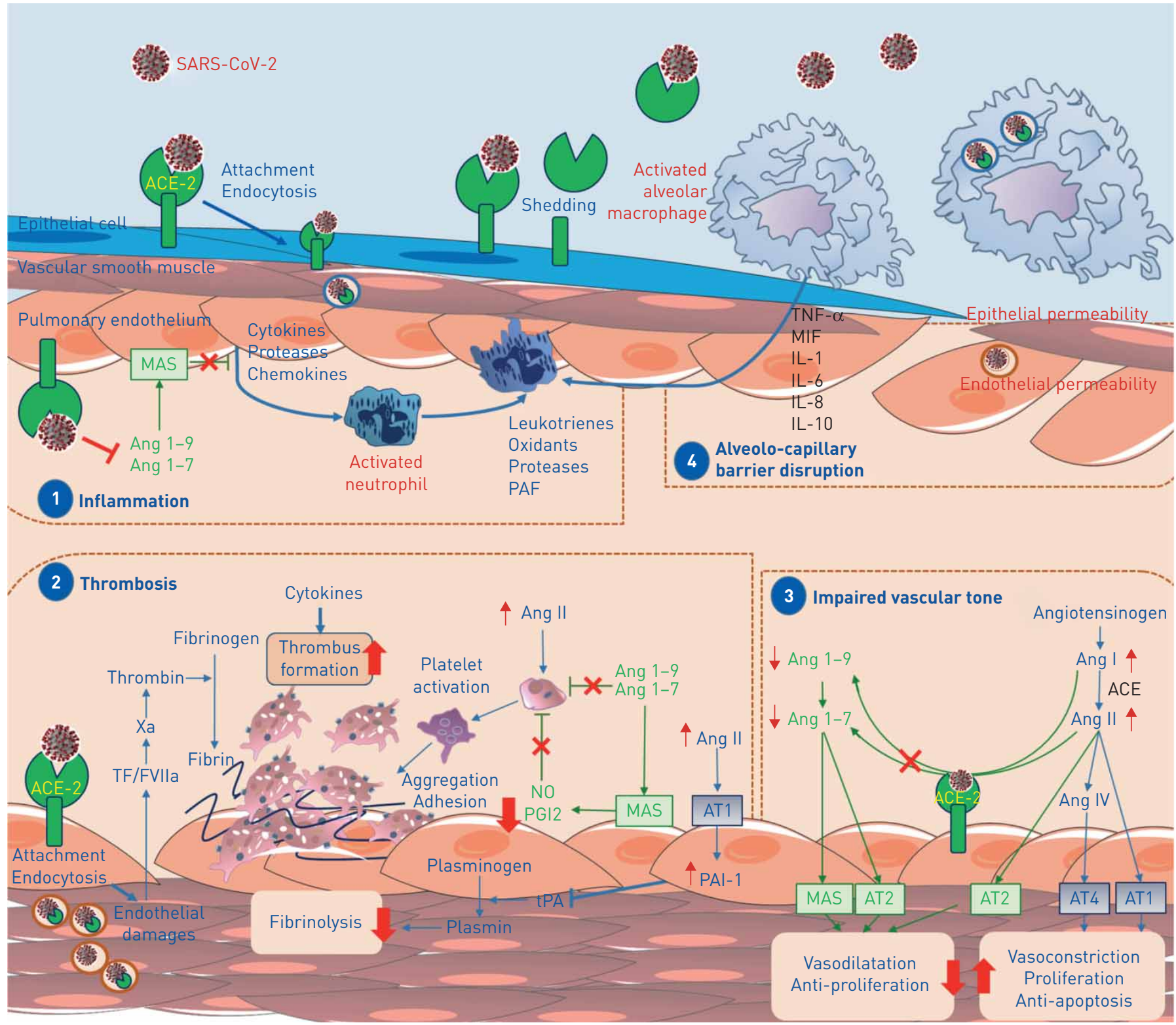

FIGURE 1 Schematic representation of hypothetical mechanisms by which the novel severe acute respiratory syndrome coronavirus 2 (SARS-CoV-2) causes endothelial dysfunction and pulmonary vascular changes. Following cleavage of its S protein, SARS-CoV-2 was reported to enter human cells via binding to angiotensin-converting enzyme 2 (ACE-2). This transmembrane ACE-2 receptor is widely expressed in various pulmonary cells including type II alveolar cells, macrophages, endothelial, smooth muscle cells and perivascular pericytes. This causes uncontrolled inflammation (1), accompanied by micro-thrombosis and occlusion of small pulmonary vessels (2), and impaired endothelial regulation of vascular tone (3), leading to alveolo-capillary barrier disruption (4). Ang: angiotensin; AT: angiotensin receptor; IL: interleukin; MAS: macrophage activation syndrome; MIF: macrophage migration inhibitory factor; NO: nitric oxide; PAF: platelet activating factor; PAl-1: plasminogen activator inhibitor-1; PGI2: prostaglandin I2; TF: tissue factor; TNF: tumour necrosis factor; tPA: tissue plasminogen activator.

mechanisms that activate coagulation in SARS-CoV-2 infection are still unknown but appear to be linked to inflammatory responses rather than specific properties of the virus [38].

KLOK et al. [39] have recently reported a 31\% incidence of thrombotic complications in COVID-19 patients in intensive care unit. GRILLET et al. [40] found that 23\% of patients with COVID-19 pneumonia had acute pulmonary embolism detected by computed tomography-pulmonary angiography. In addition, acute pulmonary oedema can be observed in critical COVID-19 patients with occlusion and micro-thrombosis of small pulmonary vessels [41]. Other researchers have hypothesised that thrombi may play a direct and significant role in gas exchange abnormalities and multisystem organ dysfunction in COVID-19 pneumonia [42]. Moreover, a few authors have pointed out a presumed role of antiphospholipid antibodies in COVID-19-related thrombotic events [43-45]. So far, it is still controversial 
whether the presence of these antibodies should be used as evidence for early anticoagulation of patients with COVID-19, knowing that antiphospholipid antibodies are common in the general population, especially during infection [46].

GATTINONi et al. [47] have highlighted that COVID-19 acute respiratory distress syndrome patients are characterised by the dissociation between relatively well-preserved lung mechanics and severe hypoxaemia. These authors have proposed that such severe hypoxaemia occurring in compliant lungs could be due to the loss of lung perfusion regulation and hypoxic vasoconstriction. This is reminiscent of the attenuated hypoxic pulmonary vasoconstriction due to pulmonary endothelial cell dysfunction induced by increased mitochondrial oxidative stress in dasatinib-exposed rodents [48]. Last, it has been shown that SARS-CoV-2 elements could be detected in endothelial cells of COVID-19 patients, together with an accumulation of inflammatory cells and evidence of endothelial and inflammatory cell death [49]. This suggests that endotheliitis could be facilitated by SARS-CoV-2 infection and induced in different organs as a direct consequence of viral infection and the host inflammatory response. Consistent with this, ACKERMANN et al. [27] found that, beyond diffuse alveolar damage with perivascular T-cell infiltration and widespread thrombosis with microangiopathy, the distinctive vascular features in COVID-19 patients consisted of severe endothelial injury associated with the presence of intracellular virus and disrupted cell membranes, as well as vascular angiogenesis.

In conclusion, the presence of SARS-CoV-2 virus within endothelial cells suggests that direct viral effects, as well as perivascular inflammation, may contribute to endothelial cell injury. It is likely that endotheliitis, endothelial injury, endothelial cell dysfunction and impaired microcirculatory function in different vascular beds contributes markedly to life-threatening complications of COVID-19, such as venous thromboembolic disease and multiple organ involvement (figure 1).

Conflict of interest: A. Huertas has nothing to disclose. D. Montani reports grants and personal fees from Actelion and Bayer, personal fees from GSK, Pfizer, Chiesi and Boehringer, grants, personal fees and non-financial support from MSD, non-financial support from Acceleron, outside the submitted work. L. Savale reports personal fees and non-financial support from Actelion and Bayer, grants and personal fees from GSK, outside the submitted work. J. Pichon has nothing to disclose. L. Tu has nothing to disclose. F. Parent reports grants from Bayer, CSL Behring and Sanofi, outside the submitted work. C. Guignabert has nothing to disclose. M. Humbert reports grants and personal fees from Actelion, Bayer, GSK and Acceleron, personal fees from Merck and United Therapeutics, outside the submitted work.

\section{References}

1 Delmas B, Gelfi J, L'Haridon $\mathrm{R}$, et al. Aminopeptidase $\mathrm{N}$ is a major receptor for the entero-pathogenic coronavirus TGEV. Nature 1992; 357: 417-420.

2 Yeager CL, Ashmun RA, Williams RK, et al. Human aminopeptidase N is a receptor for human coronavirus 229E. Nature 1992; 357: 420-422.

3 Dveksler GS, Dieffenbach CW, Cardellichio CB, et al. Several members of the mouse carcinoembryonic antigen-related glycoprotein family are functional receptors for the coronavirus mouse hepatitis virus-A59. J Virol 1993; 67: 1-8.

4 Li W, Moore MJ, Vasilieva N, et al. Angiotensin-converting enzyme 2 is a functional receptor for the SARS coronavirus. Nature 2003; 426: 450-454.

5 Holmes KV. SARS-associated coronavirus. N Engl J Med 2003; 348: 1948-1951.

6 Donoghue M, Hsieh F, Baronas E, et al. A novel angiotensin-converting enzyme-related carboxypeptidase (ACE2) converts angiotensin I to angiotensin 1-9. Circ Res 2000; 87: E1-E9.

7 Ziegler CGK, Allon SJ, Nyquist SK, et al. SARS-CoV-2 receptor ACE2 is an interferon-stimulated gene in human airway epithelial cells and is detected in specific cell subsets across tissues. Cell 2020; 181: 1016-1035.

8 Hamming I, Timens W, Bulthuis ML, et al. Tissue distribution of ACE2 protein, the functional receptor for SARS coronavirus. A first step in understanding SARS pathogenesis. J Pathol 2004; 203: 631-637.

9 Mehta P, McAuley DF, Brown M, et al. COVID-19: consider cytokine storm syndromes and immunosuppression. Lancet 2020; 395: 1033-1034.

10 Sawalha AH, Zhao M, Coit P, et al. Epigenetic dysregulation of ACE2 and interferon-regulated genes might suggest increased COVID-19 susceptibility and severity in lupus patients. Clin Immunol 2020; 215: 108410.

11 Imai Y, Kuba K, Neely GG, et al. Identification of oxidative stress and Toll-like receptor 4 signaling as a key pathway of acute lung injury. Cell 2008; 133: 235-249.

12 Chen ML, Sun A, Cao W, et al. Physiological expression and function of the MDR1 transporter in cytotoxic T lymphocytes. J Exp Med 2020; 217: e20191388.

13 Abouhashem AS, Singh K, Azzazy HM, et al. Is low alveolar type II cell SOD3 in the lungs of elderly linked to the observed severity of COVID-19? Antioxid Redox Signal 2020; 33: 59-65.

14 Matsuyama S, Nao N, Shirato K, et al. Enhanced isolation of SARS-CoV-2 by TMPRSS2-expressing cells. Proc Natl Acad Sci USA 2020; 117: 7001-7003.

15 Tortorici MA, Walls AC, Lang Y, et al. Structural basis for human coronavirus attachment to sialic acid receptors. Nat Struct Mol Biol 2019; 26: 481-489.

16 Chen Z, Mi L, Xu J, et al. Function of HAb18G/CD147 in invasion of host cells by severe acute respiratory syndrome coronavirus. J Infect Dis 2005; 191: 755-760. 
17 Guo J, Huang Z, Lin L, et al. Coronavirus disease 2019 (COVID-19) and cardiovascular disease: a viewpoint on the potential influence of angiotensin-converting enzyme inhibitors/angiotensin receptor blockers on onset and severity of severe acute respiratory syndrome coronavirus 2 infection. J Am Heart Assoc 2020; 9: e016219.

18 Mourad JJ, Levy BI. Interaction between RAAS inhibitors and ACE2 in the context of COVID-19. Nat Rev Cardiol 2020; $17: 313$.

19 South AM, Diz DI, Chappell MC. COVID-19, ACE2, and the cardiovascular consequences. Am J Physiol Heart Circ Physiol 2020; 318: H1084-H1090.

20 Chen L, Li X, Chen M, et al. The ACE2 expression in human heart indicates new potential mechanism of heart injury among patients infected with SARS-CoV-2. Cardiovasc Res 2020; 116: 1097-1100.

21 Vaduganathan M, Vardeny O, Michel T, et al. Renin-angiotensin-aldosterone system inhibitors in patients with Covid-19. N Engl J Med 2020; 382: 1653-1659.

22 Li H, Liu L, Zhang D, et al. SARS-CoV-2 and viral sepsis: observations and hypotheses. Lancet 2020; 395: 1517-1520.

23 Mancia G, Rea F, Ludergnani M, et al. Renin-angiotensin-aldosterone system blockers and the risk of Covid-19. $N$ Engl J Med 2020; 382: 2431-2440.

24 Reynolds HR, Adhikari S, Pulgarin C, et al. Renin-angiotensin-aldosterone system inhibitors and risk of Covid-19. N Engl J Med 2020; 382: 2441-2448.

25 Guzik TJ, Mohiddin SA, Dimarco A, et al. COVID-19 and the cardiovascular system: implications for risk assessment, diagnosis, and treatment options. Cardiovasc Res 2020; in press [https://doi.org/10.1093/cvr/cvaa106].

26 Luther JM, Gainer JV, Murphey LJ, et al. Angiotensin II induces interleukin-6 in humans through a mineralocorticoid receptor-dependent mechanism. Hypertension 2006; 48: 1050-1057.

27 Ackermann M, Verleden SE, Kuehnel M, et al. Pulmonary vascular endothelialitis, thrombosis, and angiogenesis in Covid-19. N Engl J Med 2020; 383: 120-128.

28 Huertas A, Guignabert C, Barbera JA, et al. Pulmonary vascular endothelium: the orchestra conductor in respiratory diseases: highlights from basic research to therapy. Eur Respir J 2018; 51: 1700745.

29 Criel M, Falter M, Jaeken J, et al. Venous thromboembolism in SARS-CoV-2 patients: only a problem in ventilated ICU patients, or is there more to it? Eur Respir J 2020; 56: 2001201.

30 Bompard F, Monnier H, Saab I, et al. Pulmonary embolism in patients with COVID-19 pneumonia. Eur Respir J 2020; 56: 2001365

31 Dolhnikoff M, Duarte-Neto AN, de Almeida Monteiro RA, et al. Pathological evidence of pulmonary thrombotic phenomena in severe COVID-19. J Thromb Haemost 2020; 18: 1517-1519.

32 Danzi GB, Loffi M, Galeazzi G, et al. Acute pulmonary embolism and COVID-19 pneumonia: a random association? Eur Heart J 2020; 41: 1858

33 Poissy J, Goutay J, Caplan M, et al. Pulmonary embolism in COVID-19 patients: awareness of an increased prevalence. Circulation 2020; 142: 184-186.

34 Ullah W, Saeed R, Sarwar U, et al. COVID-19 complicated by acute pulmonary embolism and right-sided heart failure. JACC Case Rep 2020; 2: 1379-1382.

35 Ruiz FA, Lea CR, Oldfield E, et al. Human platelet dense granules contain polyphosphate and are similar to acidocalcisomes of bacteria and unicellular eukaryotes. J Biol Chem 2004; 279: 44250-44257.

36 Engelmann B, Massberg S. Thrombosis as an intravascular effector of innate immunity. Nat Rev Immunol 2013; 13: $34-45$.

37 Connors JM, Levy JH. COVID-19 and its implications for thrombosis and anticoagulation. Blood 2020; 135: 2033-2040.

38 Becker RC. COVID-19 update: Covid-19-associated coagulopathy. J Thromb Thrombolysis 2020; 50: 54-67.

39 Klok FA, Kruip M, van der Meer NJM, et al. Incidence of thrombotic complications in critically ill ICU patients with COVID-19. Thromb Res 2020; 191: 145-147.

40 Grillet F, Behr J, Calame P, et al. Acute pulmonary embolism associated with COVID-19 pneumonia detected by pulmonary CT angiography. Radiology 2020; in press [https://doi.org/10.1148/radiol.2020201544]. 201544.

$41 \mathrm{Xu} \mathrm{Z}$, Shi L, Wang Y, et al. Pathological findings of COVID-19 associated with acute respiratory distress syndrome. Lancet Respir Med 2020; 8: 420-422.

42 Poor HD, Ventetuolo CE, Tolbert T, et al. COVID-19 critical illness pathophysiology driven by diffuse pulmonary thrombi and pulmonary endothelial dysfunction responsive to thrombolysis. Clin Transl Med 2020; in press [https://doi.org/10.1002/ctm2.44].

43 Zhang Y, Xiao M, Zhang S, et al. Coagulopathy and antiphospholipid antibodies in patients with Covid-19. $N$ Engl J Med 2020; 382: e38.

44 Harzallah I, Debliquis A, Drenou B. Lupus anticoagulant is frequent in patients with Covid-19. J Thromb Haemost 2020; in press [https://doi.org/10.1111/jth.14867].

45 Galeano-Valle F, Oblitas CM, Ferreiro-Mazon MM, et al. Antiphospholipid antibodies are not elevated in patients with severe COVID-19 pneumonia and venous thromboembolism. Thromb Res 2020; 192: 113-115.

46 Vila P, Hernandez MC, Lopez-Fernandez MF, et al. Prevalence, follow-up and clinical significance of the anticardiolipin antibodies in normal subjects. Thromb Haemost 1994; 72: 209-213.

47 Gattinoni L, Coppola S, Cressoni M, et al. Covid-19 does not lead to a "typical" acute respiratory distress syndrome. Am J Respir Crit Care Med 2020; 201: 1299-1300.

48 Guignabert C, Phan C, Seferian A, et al. Dasatinib induces lung vascular toxicity and predisposes to pulmonary hypertension. J Clin Invest 2016; 126: 3207-3218.

49 Varga Z, Flammer AJ, Steiger P, et al. Endothelial cell infection and endotheliitis in COVID-19. Lancet 2020; 395: 1417-1418. 